\title{
Knowledge and Attitude among Medical Practitioners towards Periodontal health and Diabetes
}

\author{
Veena Kalburgi ${ }^{1}$, Madhvi Singh ${ }^{2}$, Shravya $L^{3}$, \\ Sandhya Raghuvanshi ${ }^{4}$, Manish Goutam ${ }^{5}$
}

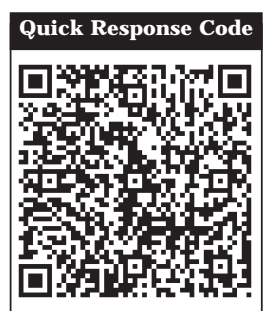

doi: $10.5866 / 2015.7 .10101$

1Prof. and Head,

2\&4Post Graduate Student

Department of Periodonitcs, Peoples Dental Acadmey, Bhopal, India

${ }^{3}$ Assistant Professor

Department Of Periodontics, Dr. Shyamla Reddy

Dental College, Bangalore

${ }^{5}$ Post Graduate Student, Department of

Prosthodontics, Rishiraj College of Dental Sciences,

Bhopal, India

\section{Article Info:}

Received: April 8, 2015

Review Completed: May 7, 2015

Accepted: J une 9, 2015

Available Online: April, 2015 (www.nacd.in)

(C) NAD, 2015 - All rights reserved

\section{Email for correspondence:}

drmadhvisinghperio@gmail.com

\begin{abstract}
:
Background: Compelling evidencelinks periodontal disease with systemic conditions of medical interest including diabetes, pregnancy complications, cardiovascular disease, respiratory diseases, osteoporosis, rheumatoid arthritis and cancer. Aims: The purpose of the study was to asses the knowledge and attitude of medical practitioners towards periodontal health and diabetes. Materials and Methods: A cross sectional questionnaire survey was carried out among 130 randomly sel ected medical doctors from two medical colleges of Bhopal including 65 Post graduate as well as 65 under graduate. Out of which 60 post graduate and 42 undergraduate student responded $(n=102)$. Questionnaire included 15 Likert scaleclose ended questions. Questions weremainly aimed to assess their knowledge and attitude towards link between diabetes and periodontal disease. The questionnaire was distributed by the investigator and it was verbally communicated that responses would remain confidential. The filled questionnaire were immediately collected after answering and analyzed through SPSS 20.0 software and Pearson's chi-square test was used to find thestatistical significance among post graduate and undergraduate medical practitioners. Results: The present study found that Bhopal Post Graduate Physicians and internists have some knowledge about oral health and think there is a link between periodontal health and diabetes; however, majority do not have knowledge about the studies that link periodontal disease and diabetes. Conclusion: The time may be right for implementing strategies in medical and dental curricula to increase inter professional education and collaboration to prepare physicians and dentists to better care for patients with diabetes and address their treatment needs.
\end{abstract}

Key words: periodontal health, diabetes, knowledge, attitude, physicians.

\section{INTRODUCTION}

The potential link between oral and systemic health has received much attention in medical and dental circles. Studies have shown potential links between oral health and nutritional deficiencies and periodontal disease in relation to cardiovascular disease, diabetes mellitus, obesity and pre-term lowbirth weight babies. ${ }^{1-5}$ While more studies need to 
be conducted before positive associations can be confirmed or rejected, it is generally accepted that the mouth can reflect the effects of systemic diseases. Compelling evidence links periodontal disease with systemic conditions of medical interest including diabetes, pregnancy complications, cardiovascular disease, respiratory diseases, osteoporosis, rheumatoid arthritis and cancer. ${ }^{6-12}$

Both diabetes mellitus and periodontal disease are chronic inflammatory diseases; the relationship that exists between the two is bi-directional. ${ }^{3,13-16} \mathrm{In}$ fact, L oe has identified periodontal disease as the sixth complication of diabetes al ong with the classic complications. In patients with diabetes and poor glycemic control the periodontium is more susceptible to infection, which increases the risk of periodontal disease, as Campus et al found in their case-control study. ${ }^{17}$ Periodontal disease in turn can exacerbate the glycemic control in patients with diabetes due to the inflammation of the periodontal tissues. This is believed to be a result of the inflammatory response to periodontal disease. Proinflammatory cytokines produced by periodontal disease aggravate the ability of the body to use insulin and can therefore disrupt the regulation of glycemiclevels. ${ }^{18}$ According to Taylor and coll leagues, subjects with diabetes and periodontal disease have a 6-fold higher risk for worsening of glycemic control over time compared to patients with diabetes who do not have periodontal disease. ${ }^{19}$ Collin and colleagues studied the periodontal status of elderly patients with Typell diabetes compared to patients without diabetes. ${ }^{20}$

\section{MATERIAL AND METHODS}

A cross sectional questionnaire survey was carried out among 130 randomly selected medical doctors from two medical colleges of Bhopal including 65 Post graduate as well as 65 under graduate. Out of which 60 post graduate and 42 undergraduate student responded $(n=102)$.

Among all respondents 92 were male and 10 were female. Questionnaire included 15 Likert scale close ended questions. ${ }^{21}$ Questions were mainly aimed to assess their knowledge and attitude towards link between diabetes and periodontal disease. The questionnaire was distributed by the investigator and it was verbally communicated that responses would remain confidential. The filled questionnaire were immediately collected after answering and analyzed through SPSS 20.0 software and Pearson's chi-square test was used to find the statistical significance among two medical practitioners.

Inclusion criteria:

1. Post graduate degree holder associated with medical colleges of Bhopal.

2. In Undergraduate students only Interns were included from medical colleges of Bhopal.

\section{RESULT}

Of the 130 questionnaires distributed, 102 completed replies were received, which is a $78 \%$ response rate. Based on their qualification 60 (58.8\%) were post graduate degree holder and 42 (41.1\%) were undergraduates. Among the sudy subjects about $97 \%(n=99)$ agreed that good periodontal health is important to overall health and $57.84 \%(n=59)$ agreed that there is strong research regarding the relationship between periodontal disease and systemic health. Based on the qualification $40 \%(n=24) P G$ doctors and $52.38 \%$ $(n=22)$ believed that research evidence is strong in association between periodontal disease and diabetes. Among the study subjects $34.13 \%(n=35)$ among which $40 \%(n=24)$ PG doctors and $50 \%$ UG doctors believed that they are knowledgeable regarding the studies linking periodontal disease and diabetes. The differences noted were found to be statistically significant ( $P \varangle 0.05$ ).

\section{Responses of the study subjects based on their attitude}

Among the study subjects $91.1 \%(n=93)$ among which $85 \%(n=51)$ PG doctors and $100 \%(n=42)$ UG doctors think that physicians should be taught about periodontal disease. Among the study subjects 59.8\% 
$(n=61)$ and based on qualification $63.3 \%(n=38 P G)$ doctors and $54.7 \%(n=23)$ UG doctors believed themselves confident that they can provide an oral health screening for their patients with diabetes.

\section{DISCUSSION}

Results of the present study showed that the medical practitioners had good knowledge about periodontal disease and diabetes as $62.7 \%$ doctors agreed that Patients with diabetes are at increased risk for severe periodontal disease. Most of the respondents agreed that good periodontal health is important to overall health. This could be because the MBBS curriculum in India includes a dental posting in which they have an exposure to dental health aspects which improves their awareness, knowledge and attitude towards oral health .Campaigns conducted by many dental product manufacturers being focused in cities which further tends to enhance their knowledge. A number of continuing medical education programs which are being conducted in Bhopal for the general medical practitioners is a great source to update their knowledge on various aspects of health.

Several studies have shown that periodontal treatment may improve glycemic control.22-25 In the present study $56.86 \%(n=58)$ were unaware of the fact that periodontal treatment may improve glycemic control. Diabetic patients generally visit to a physician for treatment so they should be acquainted about the importance of periodontal treatment effect on diabetes. Periodontal surgeons are responsibleto make medical practitioners aware regarding this which can be done with continuing medical educations, webinar, and interdisciplinary conferences.

Attitude of medical doctors was found positive and they believed that they should be taught about periodontal disease. Most of them agreed to collaborate with dental professionals to reduce their patient's risk for developing periodontal disease.

\section{Conclusion}

The present study found that Bhopal post graduate physicians and interns have some knowledge about oral health and think there is a link between periodontal health and Diabetes; however, majority do not have knowledge about the studies that link PD and DM. They believe physicians should be taught about Periodontal Disease and how to screen for Periodontal disease. They also agree that there should be collaboration between medical and dental profes-sionals to jointly educate and treat individuals with diabetes who are at risk for developing Periodontal Disease. Hopefully, one of several outcomes from this collaboration would be a decrease in Periodontal Disease for individuals with diabetes. The time may be right for implementing strategies in medical and dental curricula to increase inter professional education and collaboration to pre-pare physicians and dentists to better care for patients with diabetes and address their treatment needs.

\section{REFERENCES}

1. Soini H, Muurinen S, Routasalo 1. P et al. Oral and nutritional status - Is the MNA a useful tool for dental clinics. J Nutr Health Aging 2006; 10(6):495-499.

2. Bahekar AA, Singh S, Saha S, Molnar J, Arora R. The prevalence and incidence of coronary heart disease is significantly increased in periodontitis:a meta-analysis. Am Heart J 2007; 154(5):830-837.

3. Mealey BL, Rose LF. Diabetes mellitus and inflammatory periodontal diseases. Compend Contin Educ Dent 2008; 29(7):412-413.

4. Seymour GJ , Ford PJ , Cullinan MP, Leishman S,Yamazaki $\mathrm{K}$. Relationship between periodontal I nfections and systemic disease. Clin Microbiol Infect 2007; 13(4):3-10.

5. Bobetsis YA, Barros SP, Offenbacher S. Exploring the relationship between periodontal disease and pregnancy complications. J Am Dent Assoc 2006; 137:7-13.

6. Loe H. Periodontal disease. The sixth complication of diabetes mellitus. Diabetes Care 1993; 16:329-334.

7. J effcoat MK, Geurs NC, Reddy MS, Goldenberg RL, Hauth J C. Current evidence regarding periodontal disease as a risk factor in preterm birth. Ann Periodontol 2001; 6:183-188.

8. Beck J D, Offenbacher S. The association between periodontal diseases and cardiovascular diseases: A Stateofthescience review. Ann Periodontol 2001; 6:9-15. 
9. Garcia RI, Nunn ME, Vokonas PS. Epidemiologic associations between periodontal disease and chronic obstructive pulmonary disease. Ann Periodontol 2001; 6:71-7.

10. Wactawski Wende J. Periodontal disease and osteoporosis: Association and mechanism. Ann Periodontol 2001; 6:197-208.

11. AIKatma MK, Bissada NF, Bordeaux J M, Sue J, Askari AD. Control of periodontal infection reduces the severity of active rheumatoid arthritis. J Clin Rheumatol 2007; 13:134-137.

12. Meyer MS, J oshipura K, Giovannucci E, Michaud DS. A review of the relationship between tooth loss, periodontal disease, and cancer. Cancer Causes Control 2008; 19:895-907.

13. Southerland J H, Taylor GW, Offenbacher S. Diabetes and Periodontal I nfection: Making the Connection.Clin Diabetes 2005; 23(4):171-178.

14. Lamster IB, Lalla E, Borgnakke WS, Taylor GW. The relationship between oral health and diabetes mellitus. J Am Dent Assoc 2008; 139:19-24.

15. Amar S, Han X. The impact of periodontal infectionon systemic diseases. Med Sci Monit 2003; 9(12):291-299.

16. KimJ , Amar S. Periodontal disease and systemicconditions: a bidirectional relationship. Odontology 2006; 94(1):10-21.

17. Campus G, Salem A, Uzzau S, Baldoni E, Tonolo G. Diabetes and Periodontal Disease: A Case-Control Study. J Periodontol 2005; 76(3):418-425.

18. Tilg $\mathrm{H}$, Moschen AR. Inflammatory mechanisms in the regulation of insulin resistance. Mol Med 2008; 14(3-4):222231.
19. Taylor GW, Burt BA, Becker MP, et al. Severe periodontitis and risk for poor glycemic control in patients with noninsulin-dependent diabetes mellitus. J Periodontal 1996; 67(10):1085-1093.

20. Collin HL, Uusitupa M, Niskanen L, et al. Periodontal findings in elderly patients with non-insulin dependent diabetes mellitus. J Periodontol.1998; 69(9):962-966.

21. North Carolina Internists' and Endocrinologists' Knowledge, Opinions, and Behaviors Regarding Periodontal Disease and Diabetes: Need and Opportunity for Interprofessional Education.

22. Katagiri S, Nitta H, Nagasawa T, Uchimura I, I zumiyama $\mathrm{H}$, Inagaki K, Kikuchi T, Noguchi T, Kanazawa M, Matsuo A, Chiba H, Nakamura N, Kanamura N, Inoue S, I shikawa I, Izumi Y. Multi-center intervention study on glycohemoglobin ( $\mathrm{HbAlc}$ ) and serum, high-sensitivity CRP (hs-CRP) after local anti-infectious periodontal treatment in type 2 diabetic patients with periodontal disease. Diabetes Res Clin Pract 2009; 83:308-315.

23. Kiran M, Arpak N, Unsal E, Erdogan MF. The effect of improved periodontal health on metabolic control in type 2 diabetes mellitus. J Clin Periodontol 2005; 32: 266-272.

24. Promsudthi A, Pimapansri S, Deerochanawong C, Kanchanavasita $\mathrm{W}$. The effect of periodontal therapy on uncontrolled type 2 diabetes mellitus in older subjects. Oral Dis 2005; 11:293-298.

25. Stewart J E, Wager KA, Friedlander AH, Zadeh $\mathrm{HH}$. The effect of periodontal treatment on glycemic control in patients with type 2 diabetes mellitus. J Clin Periodontol 2001; 28:306-310.

\section{Gain quick access to our journal online View our journal at www.nacd.in}

